\title{
Complexo enzimático em rações de frango de corte de linhagem caipira com inclusão de torta da semente de cupuaçu (Theobroma grandiflorum)
}

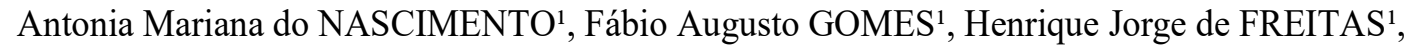 \\ Gilcineide Araújo PIRES ${ }^{2}$, Suelen Ferreira da Costa RODRIGUES ${ }^{1}$, Willyan Rodrigues do NASCIMENTO ${ }^{1}$
}

\author{
${ }^{1}$ Universidade Federal do Acre, Rio Branco, AC, Brasil. \\ *E-mail: mariana.nascimentto@hotmail.com
}

Recebido em janeiro/2018; Aceito em novembro/2018.

\begin{abstract}
RESUMO: O objetivo deste estudo foi avaliar os efeitos da suplementação de um complexo enzimático em dietas contendo torta de cupuaçu (TSC) sobre o desempenho, rendimento de carcaça e viabilidade econômica de frangos de corte de linhagem caipira. Foram utilizados 300 frangos da linhagem caipira "pescoço pelado" em delineamento experimental inteiramente casualizado com 6 tratamentos e 5 repetições. Os tratamentos, em arranjo fatorial $3 \times 2$, eram constituídos por três níveis de inclusão de TSC $(0,5,10 \%)$ e dois níveis de enzimas (sem ou com). As enzimas foram fornecidas com a inclusão de $200 \mathrm{~g} / \mathrm{t}$ de um complexo de xilanase $(12.000 \mathrm{u} / \mathrm{g})$ e $\beta$-glucanase $(2.500 \mathrm{u} / \mathrm{g})$ e $50 \mathrm{~g} / \mathrm{t}$ de fitase $(5.000 \mathrm{FTU} / \mathrm{g})$. Não houve diferença entre os tratamentos no consumo de ração e viabilidade. $\mathrm{O}$ ganho de peso diminuiu com o aumento do nível de TSC na dieta, piorando a conversão alimentar. O uso do complexo enzimático não influenciou as variáveis analisadas. O rendimento de carcaça não foi influenciado pela inclusão de TSC e complexo enzimático, porém houve diminuição da gordura abdominal e aumento da moela e intestino com o aumento da inclusão de TSC na dieta. A inclusão de TSC e complexo enzimático na dieta diminuiu a margem bruta relativa (MBR). Portanto, a inclusão de TSC afetou negativamente nas características produtivas das aves, enquanto as enzimas exógenas avaliadas não foram efetivas em compensar os efeitos deletérios da TSC no desempenho e retorno econômico.
\end{abstract}

Palavras-chave: alimentos alternativos, desempenho, enzimas, nutrição animal, rendimento de carcaça.

\section{Enzymatic complex in free-range broiler diets with inclusion of cupuaçu (Theobroma grandiflorum) seed cake}

\begin{abstract}
The purpose of this study was to evaluate with the effects of an enzyme complex supplementation in diets containing cupuaçu seed cake (CSC) on the performance, carcass yield and economic viability of freerange broilers. Three hundred broiler chickens of the 'Pescoço Pelado' free-range line were used in a completely randomized experimental design with 6 treatments and 5 replicates. Treatments, in a $3 \times 2$ factorial design, consisted of three dietary levels of CSC $(0,5$, and $10 \%)$ and two enzyme levels (without or with). The enzymes were provided by the inclusion of $200 \mathrm{~g} / \mathrm{t}$ of a xylanase $(12000 \mathrm{u} / \mathrm{g})$ and $\beta$-glucanase $(2,500 \mathrm{u} / \mathrm{g})$ complex, and by $50 \mathrm{~g} / \mathrm{t}$ phytase $(5000 \mathrm{FTU} / \mathrm{g}$ ). There was no difference on feed intake and viability. The weight gain decreased as the dietary CSM level increased, worsening feed conversion. The enzyme complex did not affected the analyzed variables. The carcass yield was not affected by the inclusion of CSC and enzyme complex, but decreased abdominal fat, and increased gizzard and intestine with dietary CSC levels increasing. The inclusion of CSC and enzyme complex in the diet reduced the relative gross margin (RGM). Therefore, the inclusion of CSC negatively affected the productive characteristics of free-range broilers, while the enzymes were not effective in compensate the CSC side effects on performance and return.
\end{abstract}

Keywords: alternative feedstuffs, animal nutrition, carcass yield, enzymes, performance.

\section{INTRODUÇÃO}

A produção de frangos de linhagem caipira antes era considerada uma atividade de subsistência de pequenos e médios produtores. Atualmente, há uma tendência dos consumidores em buscar alimentos produzidos na região em que o consumidor conheça a procedência, sendo o frango "caipira" uma alternativa para esse mercado (DOURADO, et al., 2017).

$\mathrm{Na}$ avicultura, a preocupação com a diminuição dos custos de produção é uma constante, sendo o fator alimentação um dos mais onerosos. Nesse sentido, a utilização de ingredientes alternativos pode contribuir para a redução dos custos de produção em substituição aos ingredientes convencionais, além de representar benefícios do ponto de vista comercial e sustentável, pela transformação de coprodutos e/ou resíduos agroindustriais. Por exemplo, o processamento de matérias primas para produção de cosméticos gera uma quantidade significativa de resíduos que não são próprios para alimentação humana, porém têm grande potencial na nutrição animal

A torta da semente de cupuaçu (TSC) é um resíduo da agroindústria cosmética, resultado da prensagem da semente para extração do óleo usado na fabricação de diversos cosméticos. Entretanto, seu teor de polissacarídeos não amiláceos como celulose e hemicelulose pode não ter aproveitamento pelas aves devido a ausência de enzimas 
endógenas degradadoras de fibra. O uso de enzimas exógenas nas dietas das aves pode ser uma estratégia que aliado as endógenas podem melhorar os processos de digestão e absorção, influenciando diretamente no desempenho produtivo e, consequentemente, diminuindo o custo de produção (Barbosa et al., 2014).

$\mathrm{O}$ objetivo deste estudo foi avaliar os efeitos da suplementação de um complexo enzimático (Xilanase+Betaglucanase+Fitase) em dietas contendo inclusão crescente de torta da semente do cupuaçu no desempenho zootécnico, rendimento de carcaça e análise econômica de frangos de corte tipo caipira.

\section{MATERIAL E MÉTODOS}

$\mathrm{O}$ experimento foi realizado no setor de avicultura da Universidade Federal do Acre no município de Rio Branco Acre, no período de Janeiro a Abril de 2016, localizado a uma altitude média de $187 \mathrm{~m}$, tendo como coordenadas geográficas $9^{\circ}$ 57'30' S e 67'5'06' W (ACRE, 2012) na zona tropical caracterizado por chuvas e monções (ALVARES et al., 2011).

O galpão experimental possui 16,0 $\mathrm{m}$ de comprimento por 5,0 $\mathrm{m}$ de largura, dividido em 30 (trinta) boxes de 2,0 $\mathrm{m} \times 1,5$ $\mathrm{m}$, estando disposto no sentido Leste-Oeste com pé direito de 2,8 m e coberto com telhas de fibrocimento. Possui lanternim, muretas laterais de $30,0 \mathrm{~cm}$ de altura, chão de cimento e cercado com tela de arame, bem como as divisórias internas.

Foram utilizados 300 pintos de corte do tipo caipira de um dia, machos e fêmeas, da linhagem "pescoço pelado". $\mathrm{Na}$ chegada das aves elas foram sexadas e distribuídas nas 30 unidades experimentais (6 tratamentos e 5 repetições), constituídas por 10 aves cada, em um delineamento experimental inteiramente casualizado.

Foram utilizadas lâmpadas incandescentes para aquecimento dos pintinhos na fase inicial e realizadas práticas de manejo para garantir ambiência adequada durante o período experimental. Quanto ao manejo alimentar, forneceu-se água limpa e fresca e ração à vontade durante todo o período de criação. As aves foram observadas diariamente e realizada a limpeza dos bebedouros pela manhã e tarde.

As rações foram formuladas para conter os níveis de nutrientes recomendados por Rostagno et al. (2011) (Tabela 1). Foram utilizados para formulação da ração milho e farelo de soja, com as respectivas inclusões de TSC.

A TSC (Tabela 2) foi obtida do projeto RECA (Reflorestamento Econômico Consorciado e Adensado) localizado na BR-364, km 1.071, Distrito de Nova Califórnia - Porto Velho - RO com partículas grandes, sendo necessário passar por processamento no moinho com peneira $4,5 \mathrm{~mm}$.

Tabela 1. Composição percentual das rações basais de acordo com as fases de criação.

Table 1. Percentage composition of the basal diets according to the breeding phases.

\begin{tabular}{|c|c|c|c|c|}
\hline Ingredientes & $1-14$ & $14-28$ & $28-56$ & $56-70$ \\
\hline Milho & 54,713 & 58 & 61,248 & 65,265 \\
\hline Farelo de soja - $46 \%$ & 38,656 & 35,656 & 31,665 & 27,033 \\
\hline Óleo vegetal & 2,149 & 2,43 & 3,322 & 4,146 \\
\hline Fosfato bicálcico & 1,981 & 1,84 & 1,694 & 1,535 \\
\hline Calcário calcítico & 0,95 & 0,93 & 0,873 & 0,806 \\
\hline Sal comum & 0,51 & 0,49 & 0,472 & 0,45 \\
\hline Supl. Vitamínico ${ }^{1}$ & 0,1 & 0,1 & 0,1 & 0,1 \\
\hline Supl. Mineral ${ }^{2}$ & 0,1 & 0,1 & 0,1 & 0,1 \\
\hline Dl-metionina $99 \%$ & 0,34 & 0,231 & 0,223 & 0,202 \\
\hline L-lisina $\mathrm{HCl}, 99 \%$ & 0,295 & 0,15 & 0,176 & 0,213 \\
\hline L-treonina, 98\% & 0,113 & 0 & 0,035 & 0,045 \\
\hline Salinomicina, $10 \%$ & 0,05 & 0,05 & 0,05 & 0,05 \\
\hline Colistina sulfato, $8 \%$ & 0,013 & 0,013 & 0,013 & 0,013 \\
\hline Cloreto de colina, $70 \%$ & 0,03 & 0,03 & 0,03 & 0,03 \\
\hline Total & 100 & 100 & 100 & 100 \\
\hline \multicolumn{5}{|c|}{ Composição nutricional calculada } \\
\hline $\mathrm{EM}, \mathrm{kcal} / \mathrm{kg}$ & 2950 & 3000 & 3100 & 3200 \\
\hline $\mathrm{PB}, \%$ & 22,04 & 20,96 & 19,41 & 17,98 \\
\hline Met + Cist, dig \% & 0,944 & 0,814 & 0,773 & 0,714 \\
\hline Lis, dig. \% & 1,33 & 1,148 & 1,073 & 0,992 \\
\hline Tre, dig \% & 0,865 & 0,717 & 0,697 & 0,645 \\
\hline Tri, dig \% & 0,249 & 0,235 & 0,182 & 0,191 \\
\hline Cálcio, \% & 0,939 & 0,884 & 0,824 & 0,761 \\
\hline Fósforo total $\%$ & 0,47 & 0,442 & 0,411 & 0,379 \\
\hline Sódio, \% & 0,223 & 0,214 & 0,205 & 0,195 \\
\hline \multicolumn{5}{|c|}{ Composição nutricional analisada $^{3}$} \\
\hline PB \% & 22,09 & 20,57 & 19,68 & 18,05 \\
\hline Cálcio \% & 0,943 & 0,876 & 0,819 & 0,775 \\
\hline Fósforo total $\%$ & 0,462 & 0,4501 & 0,421 & 0,383 \\
\hline Sódio, \% & 0,23 & 0,218 & 0,212 & 0,186 \\
\hline
\end{tabular}

1Suplementando por kg de ração: Vitamina A 12.000 UI, Vitamina D3 2400 UI, Vitamina E 40 UI, Vitamina K3 1,8 mg, Vitamina B1 2,5 mg, Vitamina B2 4,0 mg, Vitamina B6 2,0 mg, Vitamina B12 $15 \mu \mathrm{g}$, Biotina $60 \mu \mathrm{g}$, Niacina $30 \mathrm{mg}$, Ácido Fólico 1,8 mg. 2 Suplementando por kg de ração: Ferro $80 \mathrm{mg}$, Zinco $70 \mathrm{mg}$, Manganês $70 \mathrm{mg}$, Iodo $1 \mathrm{mg}$, Cobre $10 \mathrm{mg}$. 
Tabela 2. Composição química da TSC utilizada na dieta das aves. Table 2. Chemical composition of CSC used in free-range broiler.

\begin{tabular}{|c|c|}
\hline Variáveis & Níveis \\
\hline Proteína bruta $(\%)^{1}$ & 14 \\
\hline Energia bruta $(\mathrm{Kcal} / \mathrm{kg})^{2}$ & 4.695 \\
\hline Extrato etéreo $(\%)^{2}$ & 15,81 \\
\hline Fibra bruta $(\%)^{2}$ & 15,18 \\
\hline Material mineral $(\%)^{2}$ & 5,79 \\
\hline
\end{tabular}

Os tratamentos, em arranjo fatorial $3 \times 2$, consistiam em 3 níveis de inclusão de TSC e 2 inclusões de enzimas (sem ou com), conforme apresentado na tabela 3 . As enximas foram fornecidas na dieta pela inclusão de $200 \mathrm{~g} / \mathrm{t}$ de um complexo enzimático a base de xilanase $(12.000 \mathrm{u} / \mathrm{g})$ e $\beta$-glucanase $(2.500 \mathrm{u} / \mathrm{g})$, e pela inclusão de $50 \mathrm{~g} / \mathrm{t}$ de fitase $(5.000 \mathrm{FTU} / \mathrm{g})$.

Tabela 3. Níveis de inclusão de TSC e enzimas na dieta de frango de corte de linhagem caipira.

Table 3. Levels of inclusion of TSC and enzymes in the diet of freerange broiler.

\begin{tabular}{ccc}
\hline Trat & TSC $(\%)$ & C.E. $(\mathrm{g} / \mathrm{t})$ \\
\hline 1 & 0 & 0 \\
2 & 0 & 200 \\
3 & 5 & 0 \\
4 & 5 & 200 \\
5 & 10 & 0 \\
6 & 10 & 200 \\
\hline
\end{tabular}

A ração basal e a TSC foram pesados em balança eletrônica e o complexo enzimático e a fítase foram pesados em balança de precisão, sendo a mistura feita manualmente.

As variáveis avaliadas durante o experimento foram: Consumo médio de ração, peso vivo, conversão alimentar, viabilidade de criação e rendimento de carcaça, cortes nobres e vísceras. A avaliação das variáveis foi realizada a cada 14 dias, procedendo-se as pesagens da sobra de ração e das aves de cada tratamento.

Todas as aves de cada box foram pesadas dentro de caixas plásticas próprias para transporte de aves e em seguida calculada a média de peso de cada tratamento. O consumo de ração foi avaliado pela relação da ração fornecida no início e as sobras pesadas ao fim de cada período experimental. A conversão alimentar foi calculada pela divisão do consumo de ração pelo peso vivo das aves. A viabilidade de criação foi determinada pela seguinte fórmula: Viabilidade $=100 \%-\%$ mortalidade.

Para o abate, as aves permaneceram em jejum por oito horas. Logo após, foi realizado a insensibilização por concussão cerebral e o abate por meio do método de sangria. Em seguida as aves foram escaldadas, depenadas e esvisceradas, onde foram pesados: carcaça esviscerada (com pés e cabeça), moela, fígado, coração, intestino e gordura abdominal. Posteriormente foram feitos os cortes e pesados: peito, coxas e sobrecoxas.

Para a determinação do rendimento da carcaça, foi considerado o peso da carcaça eviscerada (com pés e cabeça), em relação ao peso vivo em jejum. Os pesos relativos do fígado, moela, coração, intestino e gordura abdominal foram calculados em relação ao peso da carcaça eviscerada (com pés e cabeça). Rendimento de coxa, sobre-coxa e peito foi determinado pela razão entre o peso do corte e peso da carcaça.
O delineamento utilizado foi o inteiramente casualizado com 6 tratamentos e 5 repetições. Foram feitos teste de média SNK para avaliação do desempenho e rendimento de carcaça por meio do programa estatístico Sisvar (FERREIRA, 2014) ao nível de 5\% de significância.

A determinação da viabilidade econômica do uso de TSC foi baseada na MBR (margem bruta relativa), calculada segundo Albino et al. (2015). Para obtenção da MBR foram calculados primeiramente o consumo de cada ingrediente por meio da fórmula:

$\mathrm{CR}$ ing. $=\frac{\text { Consumo } \mathrm{x} \% \text { ingrediente na ração }}{100}$

(Equação 1)

Os valores do consumo de ingredientes de cada tratamento foram somados para obter o consumo por tratamento (CR TRAT).

Foram feitas a multiplicação do consumo do ingrediente pelo preço do ingrediente. Com a soma dos valores dos ingredientes de cada tratamento obteve-se o consumo do tratamento $\mathrm{x}$ R $\$$ tratamento (CRTRAT $\mathrm{x}$ R\$TRAT). Foi estabelecido o preço de $14,00 \mathrm{R} \$ / \mathrm{Kg}$ do frango de corte caipira, o custo da TSC foi $0,10 \mathrm{R} \$ / \mathrm{Kg}$ e o custo da ração foi $3,95 \mathrm{R} \$ / \mathrm{Kg}$.

$\mathrm{MBR}=\frac{(\text { PFTRAT } \times \$ \mathrm{Kg})-(\text { CRTRAT } \times \mathrm{R} \$ \mathrm{TRAT})}{(\text { PFCONT } \times \text { Kg })-(\text { CRCONT } \times \text { R } \$ \text { TRAT })} \quad$ (Equação 2$)$

em que: $\mathrm{MBR}=$ Margem bruta relativa; PF TRAT $=$ Peso final do frango no nível de inclusão da TSC e adição de enzimas; $\mathrm{Kg} \$=$ Preço do quilograma de frango caipira; CR TRAT = Consumo de ração/ave no nível de inclusão da TSC e adição de enzimas; R\$ TRAT = Preço do quilograma de ração do nível de inclusão de TSC e adição de enzimas; PF CONT = Peso final do frango na dieta controle; $\mathrm{CR}$ $\mathrm{CONT}=$ Consumo de ração/ave na dieta controle; $\mathrm{R} \$ \mathrm{CONT}=$ Preço do quilograma de ração da dieta controle.

\section{RESULTADOS}

$\mathrm{O}$ consumo de ração não diferiu $(\mathrm{P}>0,05)$ entre os tratamentos em todos os períodos de criação (Tabela 4). Houve diferença $(\mathrm{P}<0,05)$ no peso das aves entre os tratamentos em todos os períodos de criação (Tabela 5), sendo que a inclusão de TSC diminuiu o peso das aves, enquanto a inclusão de enzimas não influenciou o peso das aves.

Houve diferença $(\mathrm{P}<0,05)$ na conversão alimentar entre os tratamentos em todos os períodos avaliados (Tabela 6), sendo que a inclusão da TSC nas dietas piorou a conversão alimentar dos frangos em todos os períodos de criação.

Não houve diferença $(\mathrm{P}>0,05)$ na viabilidade de criação em todos os tratamentos em todas as fases e criação (Tabela 7). Quando avaliado a inclusão de TSC e complexo enzimático, verificou-se que não houve efeito significativo no rendimento de carcaça, cortes nobres, fígado e coração $(\mathrm{P}>0,05)$ de frangos de linhagem caipira machos alimentados com TSC e CE.

Houve efeito $(\mathrm{P}<0,05)$ dos tratamentos para rendimento de moela e gordura abdominal tanto para machos (Tabela 8) quanto para fêmeas (Tabela 10) e de intestino apenas para machos (Tabela 8). A aumento da inclusão de TSC na dieta aumentou o tamanho da moela e reduziu a deposição de gordura abdominal tanto em machos quanto em fêmeas, além de aumentar o intestino dos machos. 
Tabela 4. Consumo médio de ração ( $\mathrm{kg} / \mathrm{ave}$ ) dos frangos alimentados com diferentes níveis de TSC e complexo enzimático em cada período experimental.

Table 4. Average feed intake ( $\mathrm{kg} /$ broiler) of free-range broiler fed different levels of CSC and enzymatic complex in each experimental period.

\begin{tabular}{cccccc} 
Níveis de & \multicolumn{5}{c}{ Período (Dias) } \\
\cline { 2 - 6 } Inclusão de TSC & $1-14$ & $1-28$ & $1-42$ & $1-56$ & $1-70$ \\
\hline $0 \%$ & 0,251 & 0,768 & 1,692 & 2,959 & 4,48 \\
$0 \%+$ CE & 0,262 & 0,828 & 1,964 & 3,406 & 5,144 \\
$5 \%$ & 0,259 & 0,819 & 1,765 & 3,21 & 4,877 \\
$5 \%+$ CE & 0,252 & 0,767 & 1,604 & 2,909 & 4,747 \\
$10 \%$ & 0,249 & 0,798 & 1,582 & 2,778 & 4,713 \\
$10 \%+$ CE & 0,234 & 0,866 & 1,698 & 2,767 & 4,469 \\
\hline $\mathrm{P}$ & 0,645 & 0,529 & 0,015 & 0,07 & 0,001 \\
\hline $\mathrm{CV}(\%)$ & 10,59 & 11,51 & 12,37 & 12,27 & 10,23 \\
\hline
\end{tabular}

TSC: Torta da semente do cupuaçu; CE: Complexo enzimático.

Tabela 5. Peso vivo (Kg) dos frangos alimentados com diferentes níveis de TSC com e sem complexo enzimático em cada período experimental.

Table 5. Live weight $(\mathrm{kg})$ of free-range broiler fed different levels of TSC with and without enzymatic complex in each experimental period.

\begin{tabular}{cccccc} 
Níveis de & \multicolumn{5}{c}{ Período } \\
Inclusão de & \multicolumn{5}{c}{} \\
\cline { 2 - 6 } TSC & $1-14$ & $1-28$ & $1-42$ & $1-56$ & $1-70$ \\
\hline $0 \%$ & $0,161 \mathrm{ab}$ & $0,385 \mathrm{ab}$ & $0,715 \mathrm{ab}$ & $1,234 \mathrm{a}$ & $1,764 \mathrm{a}$ \\
$0 \%+\mathrm{C}$ & $0,169 \mathrm{a}$ & $0,399 \mathrm{a}$ & $0,807 \mathrm{a}$ & $1,276 \mathrm{a}$ & $1,837 \mathrm{a}$ \\
$5 \%$ & $0,151 \mathrm{ab}$ & $0,364 \mathrm{ab}$ & $0,636 \mathrm{~b}$ & $1,016 \mathrm{~b}$ & $1,466 \mathrm{~b}$ \\
$5 \%+\mathrm{CE}$ & $0,148 \mathrm{~b}$ & $0,340 \mathrm{ab}$ & $0,611 \mathrm{~b}$ & $0,985 \mathrm{~b}$ & $1,398 \mathrm{~b}$ \\
$10 \%$ & $0,126 \mathrm{c}$ & $0,240 \mathrm{~b}$ & $0,509 \mathrm{c}$ & $0,779 \mathrm{c}$ & $1,126 \mathrm{c}$ \\
$10 \%+\mathrm{CE}$ & $0,128 \mathrm{c}$ & $0,237 \mathrm{~b}$ & $0,491 \mathrm{c}$ & $0,800 \mathrm{c}$ & $1,119 \mathrm{c}$ \\
\hline $\mathrm{P}$ & 0 & 0,0089 & 0 & 0 & 0 \\
\hline $\mathrm{CV}(\%)$ & 7,51 & 15,44 & 11,75 & 6,92 & 6,94 \\
\hline
\end{tabular}

Médias seguidas de letras diferentes nas colunas diferem estatisticamente entre si pelo teste SNK $(0,05)$. TSC: Torta da semente do cupuaçu; CE: Complexo enzimático.

Tabela 6. Conversão alimentar dos frangos alimentados com diferentes níveis de TSC com e sem complexo enzimático em cada período experimental.

Table 6. Feed conversion of free-range broiler fed different levels of CSC with and without enzymatic complex in each experimental period.

\begin{tabular}{cccccc}
\hline \multirow{2}{*}{$\begin{array}{c}\text { Níveis de } \\
\text { Inclusão } \\
\text { de TSC }\end{array}$} & $1-14$ & $1-28$ & $1-42$ & $1-56$ & $1-70$ \\
\cline { 2 - 6 } Período \\
\hline $0 \%$ & $1,554 \mathrm{a}$ & $2,038 \mathrm{a}$ & $2,431 \mathrm{a}$ & $2,394 \mathrm{a}$ & $2,534 \mathrm{a}$ \\
$0 \%+\mathrm{CE}$ & $1,548 \mathrm{a}$ & $2,084 \mathrm{a}$ & $2,583 \mathrm{a}$ & $2,667 \mathrm{ab}$ & $2,795 \mathrm{ab}$ \\
$5 \%$ & $1,714 \mathrm{ab}$ & $2,255 \mathrm{a}$ & $2,767 \mathrm{a}$ & $3,156 \mathrm{ab}$ & $3,322 \mathrm{abc}$ \\
$5 \%+\mathrm{CE}$ & $1,700 \mathrm{ab}$ & $2,280 \mathrm{a}$ & $2,640 \mathrm{a}$ & $2,964 \mathrm{abc}$ & $3,398 \mathrm{c}$ \\
$10 \%$ & $1,977 \mathrm{~b}$ & $2,770 \mathrm{~b}$ & $3,118 \mathrm{ab}$ & $3,570 \mathrm{c}$ & $3,300 \mathrm{abc}$ \\
$10 \%+\mathrm{CE}$ & $1,830 \mathrm{ab}$ & $3,035 \mathrm{~b}$ & $3,476 \mathrm{~b}$ & $3,458 \mathrm{c}$ & $4,075 \mathrm{c}$ \\
\hline $\mathrm{P}$ & 0,002 & 0 & 0,003 & 0,0002 & 0,0005 \\
\hline $\mathrm{CV}(\%)$ & 9,34 & 11,45 & 13,82 & 12,18 & 14,29 \\
\hline
\end{tabular}

Médias seguidas de letras diferentes nas colunas diferem estatisticamente entre si pelo teste SNK $(0,05)$. TSC: Torta da semente do cupuaçu; CE: Complexo enzimático.

Não houve efeito $(\mathrm{P}>0,05)$ dos tratamentos no rendimento de carcaça e de cortes nobres de machos e fêmeas (Tabela 9). A margem bruta relativa diminuiu com a inclusão de TSC e adição de enzimas (Tabela 11), possivelmente pela redução do valor recebido por animal devido a diminuição do peso de abate dos animais e, consequentemente, redução da receita bruta, apesar da diminuição do custo de arraçoamento dos frangos ter diminuído com a inclusão de TSC.

Tabela 7. Viabilidade dos frangos alimentados com diferentes níveis de TSC com e sem complexo enzimático em cada período experimental.

Table 7. Viability of free-range broiler fed different levels of TSC with and without enzyme complex in each experimental period.

\begin{tabular}{cccccc} 
Níveis de & \multicolumn{5}{c}{ Período } \\
\cline { 2 - 3 } $\begin{array}{c}\text { Inclusão de } \\
\text { TSC }\end{array}$ & $1-14$ & $1-28$ & $1-42$ & $1-56$ & $1-70$ \\
\hline $0 \%$ & 100 & 100 & 88 & 82 & 82 \\
$0 \%+$ CE & 100 & 98 & 78 & 78 & 74 \\
$5 \%$ & 100 & 100 & 92 & 88 & 88 \\
$5 \%+$ CE & 100 & 96 & 88 & 86 & 86 \\
$10 \%$ & 100 & 100 & 100 & 98 & 98 \\
$10 \%+$ CE & 100 & 100 & 98 & 94 & 94 \\
\hline P & 0 & 0,178 & 0,184 & 0,483 & 0,285 \\
\hline CV $(\%)$ & 0 & 2,92 & 15,27 & 19,7 & 19,06 \\
\hline
\end{tabular}

TSC: Torta da semente do cupuaçu; CE: Complexo enzimático.

Tabela 8. Rendimento carcaça esviscerada com pés e cabeça (CA), moela (MO), gordura abdominal (GA), intestino (IN), coração (CO), fígado (FI) de machos de linhagem caipira

Table 8. Eviscerated carcass with feet and head (EC), gizzard (GI), abdominal fat (AF), intestine (IN), heart (HE), liver (LI) of males of free-range broiler.

\begin{tabular}{|c|c|c|c|c|c|c|}
\hline \multirow{2}{*}{$\begin{array}{l}\text { Níveis de } \\
\text { Inclusão de } \\
\text { TSC }\end{array}$} & \multicolumn{6}{|c|}{ Rendimento (\%) } \\
\hline & $\mathrm{CA}$ & $\mathrm{MO}$ & GA & IN & $\mathrm{CO}$ & FI \\
\hline $0 \%$ & 77,71 & $2,37 \mathrm{~b}$ & $4,96 \mathrm{c}$ & $6,46 \mathrm{c}$ & 0,64 & 2,5 \\
\hline $0 \%+\mathrm{CE}$ & 79,13 & $2,56 \mathrm{ab}$ & $4,80 \mathrm{bc}$ & $6,81 \mathrm{c}$ & 0,66 & 1,7 \\
\hline $5 \%$ & 76,99 & $2,75 \mathrm{a}$ & $4,66 \mathrm{~b}$ & $6,21 \mathrm{c}$ & 0,7 & 2,92 \\
\hline $5 \%+\mathrm{CE}$ & 76,19 & $2,75 \mathrm{a}$ & $4,10 \mathrm{~b}$ & $8,76 \mathrm{~b}$ & 0,65 & 2,29 \\
\hline $10 \%$ & 75,12 & $2,76 \mathrm{a}$ & $4,07 \mathrm{ab}$ & $9,47 \mathrm{a}$ & 0,68 & 2,04 \\
\hline $10 \%+\mathrm{CE}$ & 73,52 & $2,79 \mathrm{a}$ & $3,80 \mathrm{a}$ & $9,64 \mathrm{a}$ & 0,66 & 2,86 \\
\hline $\mathrm{P}$ & 0,2413 & 0,0127 & 0 & 0 & 0,7905 & 0,3072 \\
\hline CV (\%) & 4,78 & 7,32 & 10,69 & 19,85 & 9,05 & 14,85 \\
\hline
\end{tabular}

Médias seguidas de letras diferentes nas colunas diferem estatisticamente pelo teste SNK $(0,05)$. TSC: Torta da semente do cupuaçu; CE: Complexo enzimático.

Tabela 9. Rendimento de Cortes nobres: Peito (PE), Coxa (COX) e Sobrecoxa (SC) de frangos de linhagem caipira.

Table 9. Yield of Noble Cuts: Chest (CH), Thigh (THI) and overcoat (OC) of broiler free-range

\begin{tabular}{|c|c|c|c|c|c|c|}
\hline \multirow{2}{*}{$\begin{array}{l}\text { Níveis de } \\
\text { Inclusão de } \\
\text { TSC }\end{array}$} & \multicolumn{3}{|c|}{ Macho } & \multicolumn{3}{|c|}{ Fêmea } \\
\hline & $\mathrm{PE}$ & COX & SC & $\mathrm{PE}$ & COX & SC \\
\hline $0 \%$ & 23,6 & 15,8 & 16,08 & 20,95 & 13,16 & 16,98 \\
\hline $0 \%+\mathrm{CE}$ & 23,3 & 15,7 & 15,85 & 21,01 & 13,35 & 17,01 \\
\hline $5 \%$ & 20,04 & 15,04 & 15,14 & 20,55 & 13,31 & 16,12 \\
\hline $5 \%+\mathrm{CE}$ & 22,15 & 14,95 & 15,41 & 20,59 & 13,15 & 16,58 \\
\hline $10 \%$ & 20,24 & 13,24 & 15,37 & 20,42 & 13,05 & 16,01 \\
\hline $10 \%+\mathrm{CE}$ & 20,18 & 13,38 & 15,14 & 20,5 & 12,98 & 16,04 \\
\hline $\mathrm{P}$ & 0,9358 & 0,501 & 0,8479 & 0,9446 & 0,9708 & 0,7612 \\
\hline CV (\%) & 19,7 & 18,01 & 10,69 & 7,5 & 6,81 & 13,24 \\
\hline
\end{tabular}

\section{DISCUSSÃO}

De maneira geral, o peso vivo dos frangos de todos os tratamentos observados neste estudo ficaram abaixo dos valores de referência para a linhagem pescoço pelado, que seria de até $0,194 \mathrm{Kg}$ aos 14 dias e 2,838 $\mathrm{Kg}$ aos 70 dias de 
idade (GLOBOAVES, 2015). Também, os pesos foram inferiores aos resultados de Silva; Ferreira (2017), que trabalhando com a linhagem pescoço pelado e inclusão de resíduos de cervejaria reportaram peso vivo final de $3,025 \mathrm{~kg}$ aos 70 dias.

Tabela 10. Rendimento carcaça esviscerada com pés e cabeça (CA), moela (MO), gordura abdominal (GA), intestino (IN), coração (CO), fígado (FI) de fêmeas de linhagem caipira.

Table 10. Eviscerated carcass with feet and head (EC), gizzard (GI), abdominal fat (AF), intestine (IN), heart (HE), liver (LI) of females of free-range broiler.

\begin{tabular}{|c|c|c|c|c|c|c|}
\hline \multirow{2}{*}{$\begin{array}{l}\text { Níveis de } \\
\text { Inclusão de } \\
\text { TSC }\end{array}$} & \multicolumn{6}{|c|}{ Rendimento (\%) } \\
\hline & $\mathrm{CA}$ & MO & GA & IN & $\mathrm{CO}$ & FI \\
\hline $0 \%$ & 77,71 & $2,51 \mathrm{ab}$ & $6,96 \mathrm{~b}$ & 7,25 & 0,64 & 2,49 \\
\hline $0 \%+\mathrm{CE}$ & 76,71 & $2,28 b$ & $6,88 \mathrm{~b}$ & 6,53 & 0,61 & 2,41 \\
\hline $5 \%$ & 75,64 & $2,68 \mathrm{a}$ & $5,85 \mathrm{~b}$ & 7,62 & 0,67 & 2,8 \\
\hline $5 \%+\mathrm{CE}$ & 73,45 & $2,64 \mathrm{a}$ & $5,71 \mathrm{~b}$ & 6,36 & 0,68 & 2,49 \\
\hline $10 \%$ & 76,59 & $2,65 \mathrm{a}$ & $5,70 \mathrm{a}$ & 7,03 & 0,63 & 2,71 \\
\hline $10 \%+\mathrm{CE}$ & 73,74 & $2,69 \mathrm{a}$ & $5,51 \mathrm{a}$ & 7,12 & 0,63 & 2,72 \\
\hline $\mathrm{P}$ & 0,0275 & 0,0079 & 0 & 0,061 & 0,0497 & 0,0731 \\
\hline CV (\%) & 2,89 & 15,07 & 15,56 & 9,47 & 5,81 & 9,15 \\
\hline
\end{tabular}

Médias seguidas de letras diferentes nas colunas diferem estatisticamente pelo teste SNK $(0,05)$. TSC: Torta da semente do cupuaçu; CE: Complexo enzimático.

Tabela 11. Margem bruta relativa (MBR) utilizando níveis de inclusão da TSC e adição de enzimas. Consumo de ração/ave dos tratamentos (CRtrat) preço do quilograma de ração dos tratamentos (R\$trat).

Table 11. Relative gross margin (RGM) using inclusion levels of CSC and addition of enzymes. Consumption of ration/bird of treatments (CRtrat) price of $\mathrm{kg}$ of ration of treatments.

\begin{tabular}{ccc}
\hline $\begin{array}{c}\text { Níveis de inclusão } \\
\text { de TSC }\end{array}$ & CR TRAT X R \$rAT $_{\text {TRA }}$ & MBR (\%) \\
\hline $0 \%$ & 4,62 & 100 \\
$0 \%+\mathrm{CE}$ & 5,06 & 98 \\
$5 \%$ & 4,48 & 73 \\
$5 \%+\mathrm{CE}$ & 4,08 & 69 \\
$10 \%$ & 3,8 & 49 \\
$10 \%+\mathrm{CE}$ & 3,85 & 48 \\
\hline
\end{tabular}

A inclusão de TSC na dieta diminuiu proporcionalmente o peso dos frangos. Estes resultados corroboraram com os obtidos por Silva et al. (2017), que observaram que quanto maior o nível de inclusão de TSC em rações de frangos de linhagem caipira, menor o peso vivo das aves.

A redução no peso vivo pode estar relacionada ao alto teor de fibra da TSC, podendo ter diminuído o aproveitamento de nutrientes da dieta. De fato, como o consumo de ração não foi influenciado pelos tratamentos, a diminuição do peso vivo dos frangos sugere uma diminuição do aproveitamento dos nutrientes da dieta, conforme evidenciado pela piora observada na conversão alimentar.

A conversão alimentar de referência de frangos da linhagem pescoço pelado é 1,650 no período de 1-14 dias e 2,559 no período 1-70 dias (GLOBOAVES, 2015). Os tratamentos com $0 \%$ de inclusão de TSC ficaram com valores médios próximos aos valores de referência, sendo 1,55 e 2,66, respectivamente. Em contrapartida, com a inclusão de TSC, a conversão alimentar piorou.

Esta piora na conversão alimentar sugere um reduzido aproveitamento total dos nutrientes da TSC, pois este ingrediente possui alta concentração de fibras solúveis e insolúveis e polissacarídeos não amiláceos (PNA's). Estes em contato com a água formam um gel que funciona como uma barreira à ação enzimática, dificultando o contato destas com as moléculas proteicas, lipídicas e amídicas do alimento, reduzindo a digestão dos alimentos e a absorção de nutrientes pelas células absortivas (BASTOS et al., 2007).

Nunes et al. (2010) também observaram piora na conversão alimentar de frangos de corte alimentados com farinha de batata doce e inclusão de um complexo enzimático composto por fitase, protease, xilanase, ß-glucanase, celulase, amilase e pectinase. $\mathrm{O}$ complexo enzimático neste estudo não foi eficiente na redução dos efeitos adversos causados pela fibra presente na TSC. A efetividade das enzimas exógenas pode ser influenciada por uma série de fatores que afetam a ação enzimática, dentre eles pode-se citar: concentrações do substrato e da enzima, temperatura, variação do $\mathrm{pH}$, umidade e presença de co-enzimas (MENEGHETTI, 2013).

Freitas et al. (2016) trabalhando com frangos Label rouge concluiu que o uso de enzimas produzidas pelo fungo Aspergillus awamori em ração basal não se justificou no experimento pois não houve diferença significativa nas características de desempenho produtivo.

Aftab (2009) em seu trabalho com dietas com farelo de algodão, canola, colza verificou que a utilização de complexo multienzimático com esses alimentos alternativos não foi eficiente em relação a ração basal. Resultados diferentes foram encontrados por Leite et al. (2011) que observaram melhora significativa na absorção de nutrientes com uso de complexo enzimático em rações a base de sorgo.

Além do fator nutricional, a viabilidade é afetada também pelas condições ambientais, sanitárias e de manejo (SOUSA, et al., 2014). Apesar dos efeitos adversos da TSC sobre o desempenho zootécnico, a TSC não influenciou na mortalidade dos frangos. Segundo Brito et al. (2016), é importante saber o rendimento de carcaça e dos cortes, pois representa a real quantidade do produto comestível a ser comercializado. Neste estudo, a inclusão de TSC e a utilização de enzimas não foram suficientes para interferir no rendimento relativo de carcaça e cortes nobres, apesar da diminuição do tamanho da carcaça e dos cortes nobres devido ao menor peso de abate. Campelo et al. (2009) trabalhando com inclusão até $53 \%$ de farinha de raiz de mandioca em rações de frangos tipo caipira também não observaram efeito sobre o rendimento de carcaça e cortes nobres.

Cardoso et al. (2011) e Dalólio et al. (2016) utilizando complexo enzimático em rações a base de milho e farelo de soja para frango de corte também não observaram diferença significativa no rendimento de carcaça e cortes nobres. Em contrapartida Aguihe et al. (2016) obtiveram melhores rendimentos de carcaça utilizando complexo enzimático em rações com inclusão de casca de mandioca em relação a ração controle.

$\mathrm{O}$ aumento no rendimento de moela e intestino se deu pela presença do alto teor de fibra bruta na TSC, pois segundo Svihus (2011) alimentos com maior teor de fibra induz o alimento a passar mais lentamente pelo trato digestivo causando hipertrofia no musculo da moela e no intestino.

Os resultados referentes ao rendimento de GA concordam com os de Silva et al. (2017), que a medida que aumentou o nível de TSC diminuiu o acúmulo de gordura abdominal.

A diminuição do rendimento de gordura pode estar associada a presença do alto teor de fibra bruta presente na 
TSC, pois a mesma interage com os ácidos biliares, resultando em maior excreção dos lipídeos e reduzindo a absorção destes e, consequentemente, diminuindo a deposição de gordura na carcaça (KRISTENSEN, et al. 2012).

$\mathrm{O}$ uso de enzimas neste estudo não exerceu efeitos positivos nos rendimentos de carcaça e cortes nobres. Segundo Kurozawa, et al. (2012), para que as enzimas tenham ação positiva é necessário que fatores como: concentrações do substrato e da enzima, temperatura, variação do $\mathrm{pH}$, umidade e da presença de coenzimas, sejam favoráveis do contrário substrato e enzima não terão interação, não havendo reação positiva.

\section{CONCLUSÕES}

A inclusão de TSC na dieta não afetou o consumo de ração, entretanto promoveu diminuição do peso vivo e piora da conversão alimentar.

$\mathrm{O}$ rendimento de carcaça e cortes nobres não foi influenciado pela TSC e enzimas, porém houve aumento no rendimento de moela, gordura abdominal e intestino das aves com a inclusão de TSC.

A margem bruta relativa diminuiu com o aumento de níveis de TSC e adição do complexo enzimático e fitase nas dietas pois, apesar da TSC ter reduzido o custo de arraçoamento, houve redução do peso de abate dos frangos e, consequentemente, da receita bruta.

\section{REFERENNCIAS}

ACRE_SECRETARIA DE ESTADO DE MEIO AMBIENTE. Plano estadual de recursos hídricos do Acre. Rio Branco: SEMA, 2012, 2012.356 p.

AFTAB U. Utilization of alternative protein meals with or without multiple-enzyme supplementation in broilers fed low-energy diets. Journal of Applied Poultry Research, Athens, v. 18 n. 2, p. 292-296, 2009. DOI: https://dx.doi.org/10.3382/japr.2008-00103

AGUiHE, P. C.; KEHINDE, A. S.; ILABOYA, I. I.; OGIALEKHE, P. Effect of dietary enzyme (maxigrain) supplementation on carcass and organ characteristics of broiler finisher chickens fed cassava peel meal based diet. International Journal of Research in Agriculture and Forestry, Lewes, v. 3, n. 6, p.192-197, 2016.

ALBINO, L. F. T.; ROSTAGNO, H. S.; SILVA, M, A.; VARGAS JÚNIOR, J. G.; FISCHER JÚNIOR, A. A.; BARBOSA, R. J. Uso de melaço em pó em ração para frangos de corte. In: Conferência apinco de ciência e tecnologia avícolas, 1997, São Paulo. Anais... São Paulo: 1997. p. 28.

ALVARES, C. A.; STAPE J. L.; SENTELHAS P. C.; DE MORAES G.; LEONARDO J.; SPAROVEK G. Köppen's climate classification map for Brazil. Meteorologische Zeitschrift, Berlin, v. 22, n. 3, p. 711-728, 2013. DOI: https://dx.doi.org/10.1127/0941-2948/2013/0507

BARBOSA, N. A. A.; BONATO, M. A.; SAKOMURA, N. K.; DOURADO, L. R. B.; FERNANDES, J. B. K.; KAWAUCHI, I. M. Digestibilidade ileal de frangos de corte alimentados com dietas suplementadas com enzimas exógenas. Comunicata Scientiae, Bom Jesus, v. 5, n. 4, p. 361-369, out/dez. 2014.

BASTOS, S. C.; FREIRE FUENTES, M. D. F.; RODRIGUES FREITAS, E.; BARRETO ESPÍNDOLA, G.; BRAGA, C. V. D. P. Efeito da inclusão do farelo de coco em rações para frangos de corte. Revista Ciência Agronômica, Fortaleza, v. 38, n. 3, p. 297-303, 2007.
BRITO, D. A. P.; BRITO, D. R. B.; GOMES A. M. N.; CUNHA, A. dos S.; SILVA FILHO, U. A.; PINHEIRO, A. A. Desempenho produtivo e rendimento de carcaça de frangos criados em diferentes materiais de cama aviária. Ciência Animal Brasileira, Goiânia, v. 17, n. 2, p. 192197, abr./jun. 2016.

CAMPELlO, C. C.; DOS SANTOS, M. D. S. V.; DOS ANJOS LEITE, A. G.; ROLIM, B. N.; CARDOSO, W. M.; SOUZA, F. M. Características de carcaça de frangos tipo caipira alimentados com dietas contendo farinha de raízes de mandioca. Ciência Animal Brasileira, Goiânia, v. 10, n. 4, p. 1021-1028, out./dez. 2009.

CARDOSO, D. M.; MACIEL, M. P.; PASSOS, D. P.; SILVA, F. V.; REIS, S. T.; AIURA, F. S. Efeito do uso de complexo enzimático em rações para frangos de corte. Archivos de zootecnia, Córdoba, v. 60, n. 232, p. 1053-1064, out./dez, 2011. DOI: http://dx.doi.org/10.4321/S0004-05922011000400021

DALÓLIO, F. S.; MOREIRA, J.; VAZ, D. P.; ALBINO, L. F. T.; VALADARES, L. R.; PIRES, A. V.; PINHEIRO, S. R. F. Exogenous enzymes in diets for broilers. Revista Brasileira Saúde Produção Animal, Salvador, v. 17, n. 2, p. 149-161, abr./jun. 2016. DOI: http://dx.doi.org/10.1590/S1519-99402016000200003

DOURADO, L. R. B.; SAKOMURA, N. K.; NASCIMENTO, D. C. N.; DORIGAM, J. C.; MARCATO S.M.; FERNANDES J. B. K. Crescimento e desempenho de linhagens de aves pescoço pelado criadas em sistema semiconfinado. Ciência e Agrotecnologia, Lavras, v. 33, n. 3, p. $875-881,2009$. DOI: http://dx.doi.org/10.1590/S141370542009000300030

FERREIRA, D. F. Sisvar: a Guide for its Bootstrap procedures in multiple comparisons. Ciência Agrotecnologica, Lavras, v. 38, n. 2, p. 109-112, 2014. DOI: http://dx.doi.org/10.1590/S1413-70542014000200001

FREITAS, P. V. D. X.; ALMEIDA, E. M.; CYSNEIROS, C. S. S.; SANTOS, J. S. Complexo enzimático em dieta para frangos Label Rouge. Nutritime Revista Eletrônica, Viçosa, v. 13, n. 3, p. 4697-4701, mai./jun. 2016.

GLOBOAVES. Manual de Manejo Linha Colonial. 2011. Disponível em: <www.globoaves.com.br>. Acesso em: 26 de dezembro de 2015.

KRISTENSEN, M.; JENSEN, M. G.; AARESTRUP, J.; PETERSEN, K. E.; SONDERGAARD, L.; MIKKELSEN, M. S.; ASTRUP, A. Flaxseed dietary fibers lower cholesterol and increase fecal fat excretion, but magnitude of effect depend on food type. Nutrition \& Metabolism, Basel, v. 9, n. 1, p. 1-8, nov. 2012. DOI: https://dx.doi.org/10.1186/1743-7075-9-8

KUROZAWA, L. E.; PARK, K. J.; HUBINGER, M. D. Influência das condições de processo na cinética de hidrólise enzimática de carne de frango. Ciência e Tecnologia de Alimentos, Campinas, v. 29, n. 3, p. 557566, jul. 2009. DOI: http://dx.doi.org/10.1590/S010120612009000300017

LEITE, P. R. S.; LEANDRO, N. S. M.; STRINGHINI, J. H.; CAFÉ, M. B.; GOMES, N. A.; JARDIM FILHO, R. M.; Desempenho de frangos de corte e digestibilidade de rações com sorgo ou milheto e complexo enzimático. Pesquisa agropecuária brasileira, Brasília, v. 46 n. 3, p. 280-286, 2011. 
MENEGHETTI, C. Associação de enzimas em rações para frangos de corte. 2013. 96f. Tese (Doutorado em Zootecnia) - Universidade Federal de Lavras, Lavras, 2013.

NUNES, J. K.; MAIER, J. C.; GONÇALVES, F. M.; GENTILINI, F. P.; ANCIUTI, M. A.; RUTZ F. Desempenho produtivo de frangos de corte alimentados com farinha de batata doce em substituição parcial ao milho, com ou sem suplementação enzimática. Ars Veterinária, Jaboticabal, v. 26 n. 3, p. 170-177, 2010.

ROSTAGNO, H. S.; DONZELE, J.; GOMES, P. C.; OLIVEIRA, R. F. de; LOPES, D. C.; FERREIRA, A. S.; TOLEDO BARRETO, S. L. de; EUCLIDES, R. F. Tabelas brasileiras para aves e suínos: composição de alimentos e exigências nutricionais. 3. ed. Viçosa: Editora UFV, 2011. 252 p.

SILVA, J. V. de A.; GOMES, F. A.; FREITAS, H. J. de; BARBOSA, M. de J. S. da S.; SILVA, J. C. T. Níveis de inclusão da torta da semente de cupuaçu na dieta de frangos caipiras criados na amazônia ocidental. Arquivos de Ciência Veterinária e Zoologia da UNIPAR. Umuarama, v. 20, n. 1, p. 1-7, jan./mar. 2017. DOI: https://dx.doi.org/10.25110/arqvet.v20i1.2017.6312

SILVA, T. R.; FERREIRA, M. W. Resíduo de cervejaria na alimentação de frangos. PUBVET, Maringá, v. 11, n. 12, p. 1188-1297, 2017.

SOUSA, M. S.; TINÔCO, I. D. F. F.; TOLEDO, S. L. B.; AMARAL, A. G.; PIRES, L. C.; FERREIRA, A. S. Determinação de limites superiores da zona de conforto térmico para codornas de corte aclimatizadas no Brasil de 22 a 35 dias de idade. Revista Brasileira Saúde Produção Animal, Salvador, v. 15, n. 2, p. 350-360, abr./jun., 2014.

SVIHUS, B. The gizzard: function, influence of diet structure and effects on nutrient availability. World's Poultry Science Journal, Ithaca, v. 67, n. 2, p. 207-224, jun. 2011. DOI: https://dx.doi.org/10.1017/S0043933911000249 